\title{
Engineering of a rough auxotrophic mutant Salmonella Typhimurium for effective delivery
}

\author{
Jonathan Lalsiamthara ${ }^{1}$, Je Hyoung Kim ${ }^{1}$ and John Hwa Lee ${ }^{1}$ \\ ${ }^{1}$ College of Veterinary Medicine, Chonbuk National University, Iksan Campus, Iksan 54596, Republic of Korea \\ Correspondence to: John Hwa Lee, email: johnhlee@jbnu.ac.kr \\ Keywords: Salmonella Typhimurium; live-attenuated bacterial vector; pre-existing immunity; heterologous antigen delivery \\ Received: September 05, $2017 \quad$ Accepted: April 05, $2018 \quad$ Published: May 22, 2018 \\ Copyright: Lalsiamthara et al. This is an open-access article distributed under the terms of the Creative Commons Attribution Li- \\ cense 3.0 (CC BY 3.0), which permits unrestricted use, distribution, and reproduction in any medium, provided the original author \\ and source are credited.
}

\section{ABSTRACT}

Live Salmonella vaccine vectors offer a remarkable platform for delivering immunogens and therapeutic molecules by mimicking natural intracellular infections; however, pre-existing anti-vector immunity can impede effective deployment. Measures to alleviate pre-existing immunity include the use of heterologous vectors, development of highly attenuated strain enabling greater payload, removal of major immunoreactive components from the vector, and/or augmentation of delivered antigens via increased presentation in antigen presenting cells. Here we report a Salmonella Typhimurium (ST) vector-JOL1800 that embodies these requisite properties. JOL1800 is a highly attenuated, auxotrophic, and O-antigen deficient rough-mutant strain. Heterologous bacterial and viral antigens were expressed and delivered using JOL1800 in mice, irrespective of the inoculation route successful inductions of the mucosal and systemic humoral responses were observed. Compared to smooth LPS vector delivery, we observed an increased fraction of delivered-antigen presenting dendritic cells and a higher frequency of delivered-antigen displayed per macrophage. Upon post-priming with JOL1800 delivery, efficacy of the delivery was minimally affected as indicated by insignificant decrease in colonization, humoral and cellular responses. Our results show that the generated vector is capable of remote antigen delivery, manifests higher antigen presentation, is Differentiating Infected from Vaccinated Animals (DIVA) capable, evades normal pre-existing immunity, and can be deployed for effective delivery.

\section{INTRODUCTION}

Salmonella enterica serovar Typhimurium (ST) is a gram-negative intracellular pathogen and is one of the most extensively studied organisms particularly in the areas of basic science research, systemic bacterial infections, immunological profiling, and host resistance to pathogens. It is also widely studied for its use as a vaccine and live vector vaccine and also as an anti-tumor vector due to its intrinsic properties [1,2]. With advancements in genetic engineering and synthetic biology, modified ST are designed to deliver a diverse range of payloads such as immunogens, heterologous antigens, therapeutic, and antitumor drug molecules [3]. The intracellular localization of ST allows for the cytosolic delivery of drugs and cytotoxic proteins that are otherwise unable to enter eukaryotic cells.
ST is a facultative pathogen that is found within a variety of phagocytic and non-phagocytic cells [4]. Hence, a live ST vector that constitutively expresses beneficial proteins would deliver the antigen to various tissues of the host including systemic as well as mucosal sites.

Characteristics of an ideal bacterial delivery vector include sufficient attenuation, active antigen-presenting cell recognition, and stable maintenance of antigen coding-recombinant plasmid vector. In order to achieve attenuation, ST mutants deficient in the biosynthesis of metabolic precursors, energy carriers, or mutants defective in the global regulatory system have been the most widely characterized [5-7]. These mutants are excellent carriers for vaccine antigens from other bacteria $[8,9]$, viruses [10, 11], parasites [12-14], and tumors [15, 16] and are able to stimulate strong systemic and local 
immune responses against the corresponding antigens [17]. In this study, an attenuated mutant ST strain that was devoid of virulence-associated bacterial regulatory genes lon and cpxR [18, 19], was attenuated further via deletion of a gene that is involved in LPS biosynthesis pathway. It is known that deficiency in LPS resulted in increased sensitivity to complement mediated killings and renders the rough bacterial strains avirulent [20]. Rough Salmonella have been evaluated and tested extensively as a vaccine candidate [21-23]; however, to date, very few rough strains have been tested as a live vector vaccine [24]. Recently, our group has extensively employed smooth or rough Salmonella vectors for delivering mucosal adjuvants and Brucella antigens, and their application as vaccine candidates [25-27]. It has been demonstrated that $\mathrm{O}$-antigen (O-Ag) of the Salmonella lipopolysaccharide (LPS) as an important factor for controlling the intracellular fate of Salmonella in dendritic cells (DC). A Salmonella strain without O-Ag showed an increased rate of uptake by DC and altered intracellular processing and increased degradation, which boosted the DC immune function [28]. Stable host-plasmid maintenance was attained via an antibiotic free, balancedlethal host-vector system. An auxotrophic asd negative ST strain was complemented with plasmid-encoded aspartate semialdehyde dehydrogenase [27].

Despite potential and promise, the biggest challenge in implementing successful delivery depends in large part on the presence or absence of pre-existing immunity. Preexisting anti-Salmonella immunity can impede repetitive use of the vector for the delivery of immunogens and therapeutic molecules [29, 30]. Measures that can alleviate these limitations include switching the ST serotype on subsequent deliveries or boosting at an appropriate time [29], administration of higher vector vaccine doses [31], and exposure of the host to the candidate antigen prior to vector-priming [32]. However, with ST-based vectors, preexisting immunity may not be completely avoidable mainly due to the ubiquitous presence of Salmonellae in food and in the water system and also due to its endemic propensity in livestock and the human population [33]. Based on our hypothesis, an alternative approach to improve the ST vector would involve development of a highly attenuated strain that is safe even at high doses and thus yields higher payload delivery, removal of major bacterial surface immunoreactive components such as LPS [34] from the vector, and augmentation of delivered antigens via increased presentation in antigen-presenting cells.

Finally, removal of a portion of Salmonella LPS renders the organism insensitive to anti-LPS antibodies. Most surveillance agencies for food safety and Salmonella programs use LPS-based ELISA as detection [35]. Hence, a delivery system lacking a complete LPS would not interfere with Salmonella diagnostic programs. Hence, the added advantage of using a rough ST strain as a live vector vaccine include Differentiation of Infected and Vaccinated Animals (DIVA) capability, safer attenuated phenotypic profile, circumvention of pre-existing antibodies, and a broad range of cross protection.

Considering all of the practical advantages, we engineered a rough ST live bacterial vector vaccine, designated as JOL1800. We report here the development and characterization of an $r f a L$ gene knock out O-Ag deficient mutant strain. The $r f a L$ gene encodes for $\mathrm{O}$-antigen ligase that adds the O-antigen on the glucose (II) group of LPS. To investigate the antigen delivery capabilities of the developed strain in this study, heterologous bacterial and viral antigens were expressed and delivered using JOL1800 through mucosal and systemic routes in mice. Antigen specific humoral responses were studied, including examining the presentation of delivered-antigens in DC and intraperitoneal macrophages, the effect of pre-existing antiST wild type immunity on delivery, and DIVA ability of the strain based on LPS indirect ELISA.

\section{RESULTS}

\section{Construction and validation of JOL1800}

In order to combine the properties of an ideal live vaccine vector, JOL1800 was engineered based on the highly immunogenic and invasive parental smooth ST strain JOL912 [36] (Table 1). JOL912 $(\Delta l o n \Delta c p x R \Delta a s d)$ is a triple gene knockout auxotrophic mutant that requires complementation of the asd gene to replicate. Dependence on the $a s d+$ plasmid vector creates a balanced-lethal complementation between the host and the plasmid construct. A non-reverting $r f a L$ deletion mutant was constructed using the red lambda recombineering approach. The O-Ag ligase gene $\mathrm{rfaL}$ was deleted from the JOL912 genome to generate the $\Delta l o n \Delta c p x R \Delta a s d \Delta r f a L$ knockout mutant JOL1800. The deletion event was confirmed by using outer and inner PCR primers that detect the flanking regions of the target gene. Upon replacement of wild type $r f a L$ with a cat $^{R}$ gene cassette $(\sim 1.1 \mathrm{~kb})$, the original amplicon size of $1.9 \mathrm{~kb}$ was reduced to $1.7 \mathrm{~kb}$ in the mutant type. PCR primers designed to amplify the internal $r f a L$ sequence yielded no amplification in the mutant strain (Supplementary Figure 1). Silver stains of PAGEseparated purified LPS extracts from JOL1800 revealed the absence of the major O-Ag (Figure 1A), while the wild type strains showed the complete LPS pattern. To ascertain bacterial morphology and surface integrity, JOL1800 was subjected to electron microscopy analysis. Despite multiple genes affecting membrane synthesis (i.e., asd, rfaL genes) and disruption of flagella-assembly, weakened or disrupted membrane structures were not evident from direct EM observation (Supplementary Figure 2A). 
Table 1: Bacterial strains, plasmids and primers used in this study

\begin{tabular}{|c|c|c|}
\hline $\begin{array}{l}\text { Strain/ } \\
\text { plasmid/ } \\
\text { primers }\end{array}$ & Description & Reference \\
\hline JOL401 & 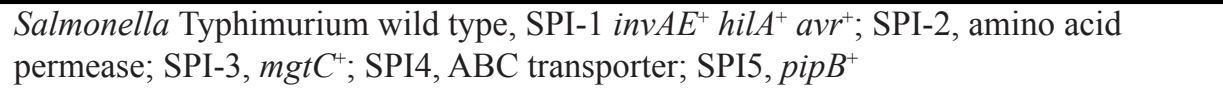 & {$[53]$} \\
\hline JOL912 & JOL401 $\Delta l o n, \Delta c p x R, \Delta a s d ;$ smooth ST strain & [36] \\
\hline JOL1800 & $\begin{array}{l}\text { JOL912 } \Delta r f a L \text {, O-antigen deficient strain, improved bacterial delivery vector; rough } \\
\text { ST strain }\end{array}$ & This study \\
\hline JOL912L & $\begin{array}{l}\text { JOL912 delivering heterologous bacterial antigen-autotransporter protein A (LatA) } \\
\text { via pJHL65-L }\end{array}$ & Lab stock \\
\hline JOL401H & JOL401 delivering viral antigen-hemagglutinin (HA) via pJHL65-H & Lab stock \\
\hline JOL912H & JOL912 delivering viral antigen-hemagglutinin (HA) via pJHL65-H & Lab stock \\
\hline JOL912B & $\begin{array}{l}\text { JOL912 delivering heterologous bacterial antigen-Brucella lumazine synthase (BLS) } \\
\text { via pJHL65-B }\end{array}$ & {$[25]$} \\
\hline JOL1800L & $\begin{array}{l}\text { JOL1 } 1800 \text { delivering heterologous bacterial antigen-autotransporter protein A (LatA) } \\
\text { via pJHL65-L }\end{array}$ & This study \\
\hline JOL1800H & JOL1800 delivering viral antigen-hemagglutinin (HA) via pJHL65-H & This study \\
\hline JOL $1800 \mathrm{~B}$ & $\begin{array}{l}\text { JOL1800 delivering heterologous bacterial antigen-Brucella lumazine synthase (BLS) } \\
\text { via pJHL65-B }\end{array}$ & {$[25]$} \\
\hline \multicolumn{3}{|l|}{ Plasmids } \\
\hline pKD46 & $\begin{array}{l}\text { oriR101-repA101ts; encodes lambda red genes (exo, bet, gam); native terminator } \\
\text { (tL3); arabinose-inducible promoter for expression (ParaB); bla }\end{array}$ & {$[52]$} \\
\hline pKD3 & oriR6Kgamma, bla $\left(\mathrm{amp}^{\mathrm{R}}\right), \operatorname{rgn} B($ Ter $)$, cat ${ }^{\mathrm{R}}, \mathrm{FRT}$ & {$[52]$} \\
\hline pCP20 & $\begin{array}{l}\text { helper plasmid, contains a temperature-inducible } f l p \text { gene for removing the } \\
\text { chloramphenicol resistance gene }\end{array}$ & {$[52]$} \\
\hline pJHL65 & $\begin{array}{l}\text { asd }+ \text { vector, } \mathrm{pBR} \text { ori, } \beta \text {-lactamase signal sequence-based periplasmic secretion } \\
\text { plasmid, } 6 \mathrm{xHis} \text {, high copy number plasmid }\end{array}$ & {$[58]$} \\
\hline pJHL65-L & $\begin{array}{l}\text { pJHL65 harbouring Lawsonia intracellularis latA gene (Lawsonia auto-transporter } \\
\text { protein A) constitutively express under Ptrc promoter, secreted under bla secretory } \\
\text { system }\end{array}$ & Lab stock \\
\hline pJHL65-H & $\begin{array}{l}\text { pJHL65 harbouring HA gene (low pathogenic avian influenza), constitutively express } \\
\text { under Ptrc promoter, secreted under bla secretory system }\end{array}$ & Lab stock \\
\hline pJHL65-B & $\begin{array}{l}\text { pJHL65 harbouring Brucella abortus (BLS) gene, constitutively express under Ptrc } \\
\text { promoter, secreted under bla secretory system }\end{array}$ & {$[25]$} \\
\hline \multicolumn{3}{|l|}{ Primers } \\
\hline rfaL P1 & 5'-tgtctcatcccaaacctattgtggagaaaagatgctaaccGTGTAGGCTGGAGCTGCTTC & This study \\
\hline rfaL P2 & 5'-atgatggaaaacgcgctgataccgtaataagtatcagcgcATGGGAATTAGCCATGGTCC & \\
\hline rfaL DEL OT & & This study \\
\hline $\mathrm{F}$ & 5'-GGATACGATAAACCGCAGTCG & \\
\hline \multicolumn{3}{|l|}{ rfaL DEL OT } \\
\hline $\mathrm{R}$ & 5'- AACCGTGCGCTTGCTGATAAG & \\
\hline rfaL DEL IN F & 5'- ACAAGTTTAGGACTTCGCTGCC & This study \\
\hline rfaL DEL IN R & 5'-CAGAATGGTATTATGCGGACCG & \\
\hline TYPH-F & 5'-TTGTTCACTTTTTACCCCTGAA & {$[54]$} \\
\hline TYPH-R & 5'-CCCTGACAGCCGTTAGATATT & \\
\hline
\end{tabular}

\section{Removal of O-Ag from JOL1800 increased sensitivity to serum complement}

To characterize the phenotype of JOL1800 and to verify that the mutation resulted in a surface phenomenon, in vitro complement sensitivity assays were performed. We also investigated the effects of the complement to mediate bacterial cell lysis on the shortened O-Ag side chain strain. The JOL1800 rough strain was more sensitive to rabbit complement death than were the smooth strain 
counterparts (Figure 2). A significant reduction in bacterial count was observed compared to the wild type smooth strain JOL401 and parental smooth strain JOL912. In addition, we observed an increased sedimentation rate of the JOL1800 broth culture (Supplementary Figure 2B) and a marked acriflavine dye-agglutination of JOL1800 colonies (Supplementary Figure 2B). Rough strains of Salmonella have increased surface hydrophobicity upon removal of O-Ag, which increases auto-agglutination of the bacterial cells and thus imparts mass formation and quicker sedimentation.

\section{Attenuated JOL1800 persists long enough in the murine spleens to induce an effective immune response}

Multiple gene mutations tend to yield extremely attenuated progeny strains, and some rough strains fail to reach target organs and fail to effectively colonize. Balanced attenuation is essential, where the ST strains should neither reside too long in the host, leading to chronicity, nor too short, resulting in failure to mount robust immunity. To ascertain the persistence of JOL1800 in the host system, splenic bacterial clearance interval was determined. Spleens of JOL-strain infected mice were homogenized in PBS, and the homogenate was directly plated; simultaneously, the remaining homogenate was subjected to further selective enrichment. All JOL401, JOL912, and JOL1800 strains were detected in the spleens of mice at 3, 7, and 14 days post inoculation, with varying levels of bacterial load (Table 2). JOL401 and JOL912 were detected beyond 14 days post inoculation. The recovery time $\left(\mathrm{RT}_{50}\right)$ of JOL401, JOL912, JOL1800oral, and JOL1800-IM were determined as 25.0, 15.8, 6.0, and 5.2 days, respectively (Supplementary Figure 3), indicating that JOL1800 is more attenuated than the other strains but also sufficiently resides in the host system long enough to efficiently deliver antigen and induce the host immune response. Splenomegaly was observed in JOL401-infected mice, while milder splenic enlargements were observed in mice infected with JOL912 or JOL1800 (Supplementary Figure 4).

\section{Live ST vector can remotely activate systemic and mucosal immunity by delivering immunogens to afflicted sites, irrespective of immunization site}

The versatility of JOL1800 in delivering diverse heterologous bacterial/viral antigens and thereby
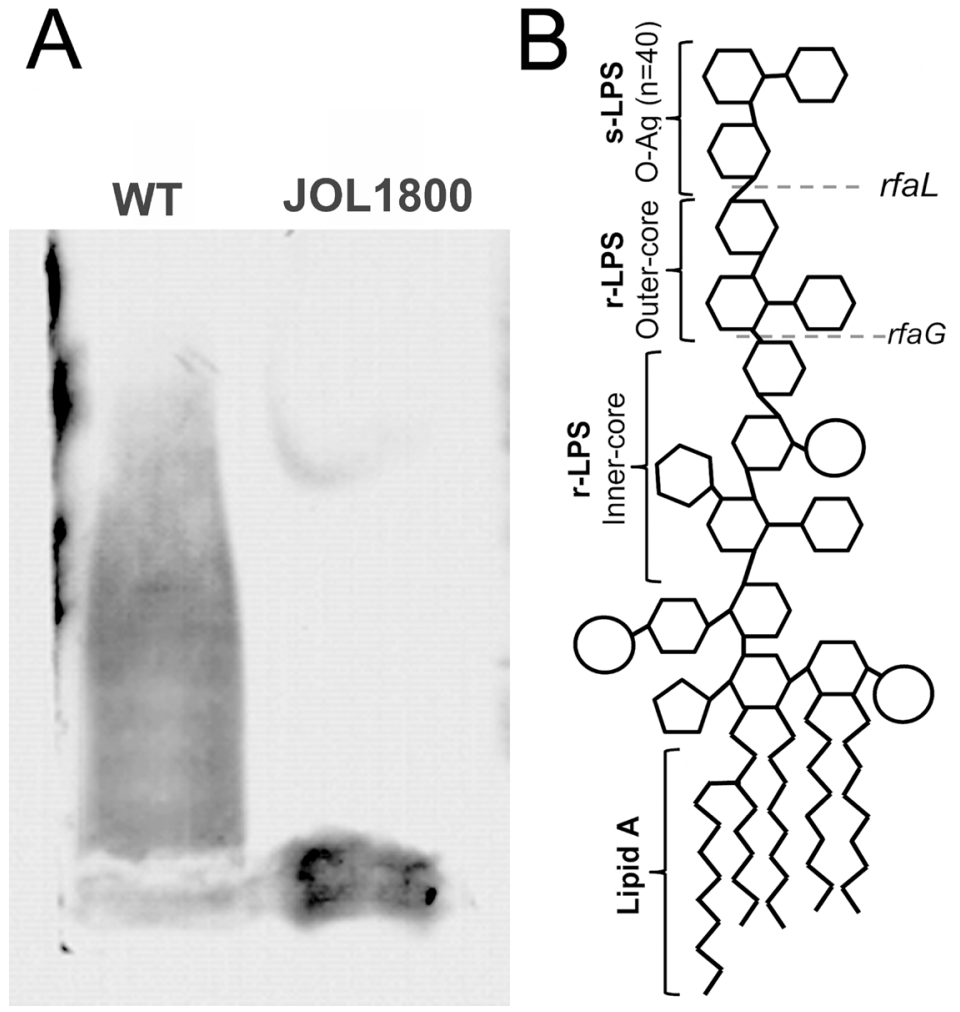

Figure 1: Salmonella LPS smooth and rough. LPS from wild type ST and rough ST JOL1800 strains was extracted suing phenol based technique. Purified LPS was subjected to $15 \%$ SDS-PAGE electrophoresis. Separated LPS was stained with silver stain after periodic acid oxidation. (A) Lane 'WT' depicts wild type LPS with complete O-antigen. Lane 'JOL1800' depicts rough type LPS without O-antigen. (B) Schematic representation of Salmonella LPS (Adapted and modified for Kong et al. 2011 [24]). Dotted lines represent units affected by rfaL gene deletion. 
elicit the humoral immune response was investigated. Mice were inoculated with JOL912 and JOL1800 strains constitutively expressing the bacterial and viral antigens, Lawsonia auto-transporter protein A (LA) and hemagglutinin from H1N1 (HA), respectively. Murine $\mathrm{IgG}$ and SIgA antibody production against the specific antigens was determined using indirect ELISA (Figure 3). Further, to validate the hypothesis that live ST delivery can evoke humoral responses against delivered antigens remotely, anti-LA and anti-HA antibodies were determined from murine intestinal lavage samples after IM (systemic) immunization, and vice versa, for systemic serum IgG from mice immunized via the oral (mucosal) route. Interestingly, production of SIgA specific for deliveredantigens were detected in intestinal lavage samples from groups immunized via the IM route. This confirmed that live ST variants reached intestinal mucosal immune-sites following systemic immunization and has the ability to activate systemic as well as mucosal immunity.

\section{The JOL1800 live vaccine vector is DIVA- capable}

To validate the DIVA potential of the JOL1800 delivery system, reactivity of inoculated mice serum IgG with purified ST LPS was tested using indirect ELISA format. Relative $\mathrm{OD}_{492}$ levels were determined between the sera of JOL401, JOL912, and JOL1800 inoculated mice (Figure 4). The smooth strains JOL401 and JOL912 induced LPS specific antibodies in the inoculated mice, while JOL1800 did not induce detectable levels. To further rule out that the JOL1800 strain could be extremely attenuated and thus incapable of inducing any LPS specific bodies, a booster dose was given 3 weeks post inoculation. The booster dose did not further enhance the production of anti-LPS antibodies in JOL1800 immunized mice, which confirmed the DIVA potential of the JOL1800 strain.

\section{JOL1800-delivered antigens are more highly displayed on antigen-presenting cells}

To investigate and quantify in vivo DC uptake and antigen presentation elicitation of the JOL1800 delivery system, mice were inoculated via oral or IM with JOL401H, JOL912H, and JOL1800H ST strains expressing and delivering the HA antigen. Mice were euthanized, and splenocytes were harvested. The fraction of dendritic cells (DCs) presenting delivered antigen was determined on total murine splenocytes using flow cytometric analysis (FACS). The DC population was gated with anti-CD11cFITC, and the delivered antigen HA protein was detected using rabbit anti-HA primary antibody and anti-rabbit IgGAlexaFluor647 (Figure 5). The frequency of DC displaying HA was $6.22 \% \pm 2.36,6.63 \% \pm 1.65,10.36 \% \pm 1.23$, and

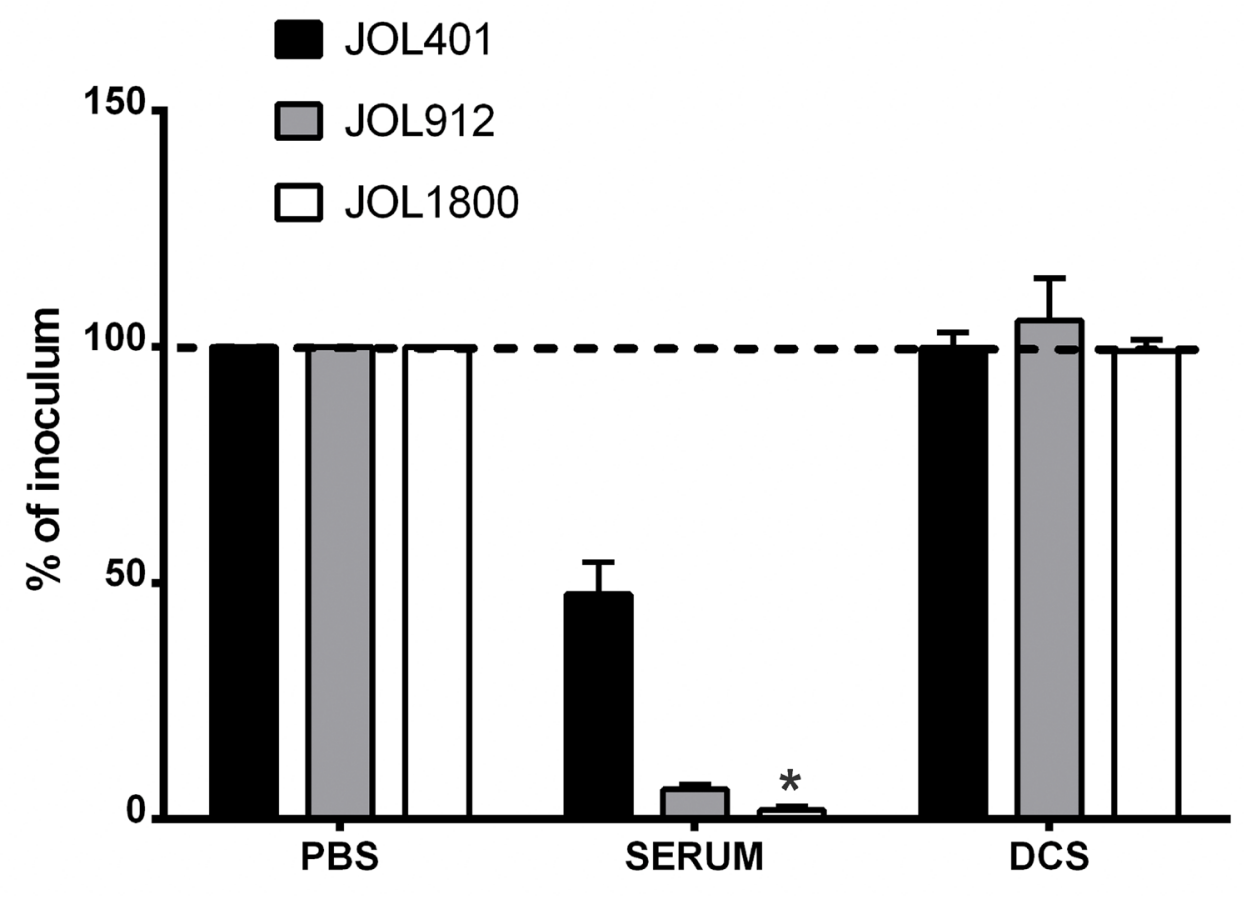

Figure 2: Sensitivity to complement killing. Salmonella strains were evaluated for sensitivity to serum complement. Bacterial strains namely, wild type strain (JOL401), smooth strain (JOL912) and rough strain (JOL1800) were incubated with 50\% fresh rabbit complement for $1 \mathrm{hr}$ at $37^{\circ} \mathrm{C}$. The degree of reduction due to complement activity was ascertained following plating on BGA plates. The rough strain JOL1800 showed increase sensitivity to complement killing. DCS- de-complemented serum. ${ }^{*}$ indicates significant difference $(P \leq 0.05)$ as compared to corresponding wild type control. 
Table 2: Splenic bacterial recovery of ST strains

\begin{tabular}{|c|c|c|c|c|c|c|c|c|}
\hline \multirow[t]{2}{*}{ Strain } & \multicolumn{2}{|c|}{$3^{a}$} & \multicolumn{2}{|c|}{7} & \multicolumn{2}{|c|}{14} & \multicolumn{2}{|c|}{21} \\
\hline & $\log _{10}$ & $\begin{array}{c}\text { No. of } \\
\text { positive }\end{array}$ & $\log _{10}$ & No. of positive & $\log _{10}$ & $\begin{array}{c}\text { No. of } \\
\text { positive }\end{array}$ & $\log _{10}$ & $\begin{array}{c}\text { No. of } \\
\text { positive }\end{array}$ \\
\hline JOL401 & $3.06 \pm 0.08^{b}$ & $8 / 8^{c}(8)^{d}$ & $2.67 \pm 0.09$ & $8 / 8(8)$ & $2.46 \pm 0.16$ & $8 / 8(7)$ & $2.03 \pm 0.18$ & $7 / 8(5)$ \\
\hline JOL912 & $1.26 \pm 0.28^{*}$ & $8 / 8(7)$ & $1.93 \pm 0.47$ & $7 / 8(6)$ & $0.67 \pm 0.38^{*}$ & $6 / 8(5)$ & $0.47 \pm 0.23^{*}$ & $2 / 8(0)$ \\
\hline JOL1800 ORAL & $0.64 \pm 0.36^{*}$ & $8 / 8(8)$ & $1.59 \pm 0.15^{*}$ & $6 / 8(4)$ & $0.30 \pm 0.17^{*}$ & $4 / 8(3)$ & $0.0^{*}$ & $0 / 8(0)$ \\
\hline JOL1800 IM & $0.73 \pm 0.19^{*}$ & $8 / 8(7)$ & $1.74 \pm 0.14^{*}$ & $7 / 8(5)$ & $0.10 \pm 0.10^{*}$ & $3 / 8(2)$ & $0.0^{*}$ & $0 / 8(0)$ \\
\hline
\end{tabular}

adays post inoculation.

${ }^{b}$ mean $\log 10$ splenic count \pm standard error of mean.

${ }^{c}$ total number of mice positive of ST strain by total number of mice screened.

dnumber of ST positive mice detected by direct BGA plating, without RV broth enrichment.

Asterisk *indicates significant difference $(P \leq 0.05)$ as compared to corresponding wild type strain JOL401 for each corresponding day post inoculation.

$12.32 \% \pm 3.19$ for JOL401H, JOL912H, JOL1800H Oral, and JOL1800H IM, respectively. Significant frequency difference $(p \leq 0.05)$ was observed between the smooth and rough type strains.

To visualize the magnitude of antigenic display at the cellular level, murine intraperitoneal macrophages were infected in vitro at 10:1 MOI with hemagglutinin delivering ST strains (Figure 6; Supplementary Figure 5). At $16 \mathrm{~h}$ post infection, the cells were fixed and subjected to immunofluorescence microscopic analysis. Wild type JOL401H, which was more resistant to lysosomal degradation, was seen almost intact inside the macrophages, and minimal ST antigen or HA antigen was observed. Macrophages infected with JOL1800H showed maximal display of ST and HA antigens, followed by JOL912H. Hence, direct visualization revealed that antigenic display and presentation were increased not only in the cell population, but also in individual cells. Collectively, the FACS data and immunofluorescence microscopic analysis confirmed enhancement of antigenic display of the rough ST vector and the delivered antigen by antigen-presenting cells.

\section{Pre-existing wild type ST-immunity has minimal effect on the efficacy of JOL1800 antigen delivery}

To assess the effect of pre-existing antibodies on the bacterial vector and to validate whether removal of LPS could minimize vector colonization and efficacy, mice

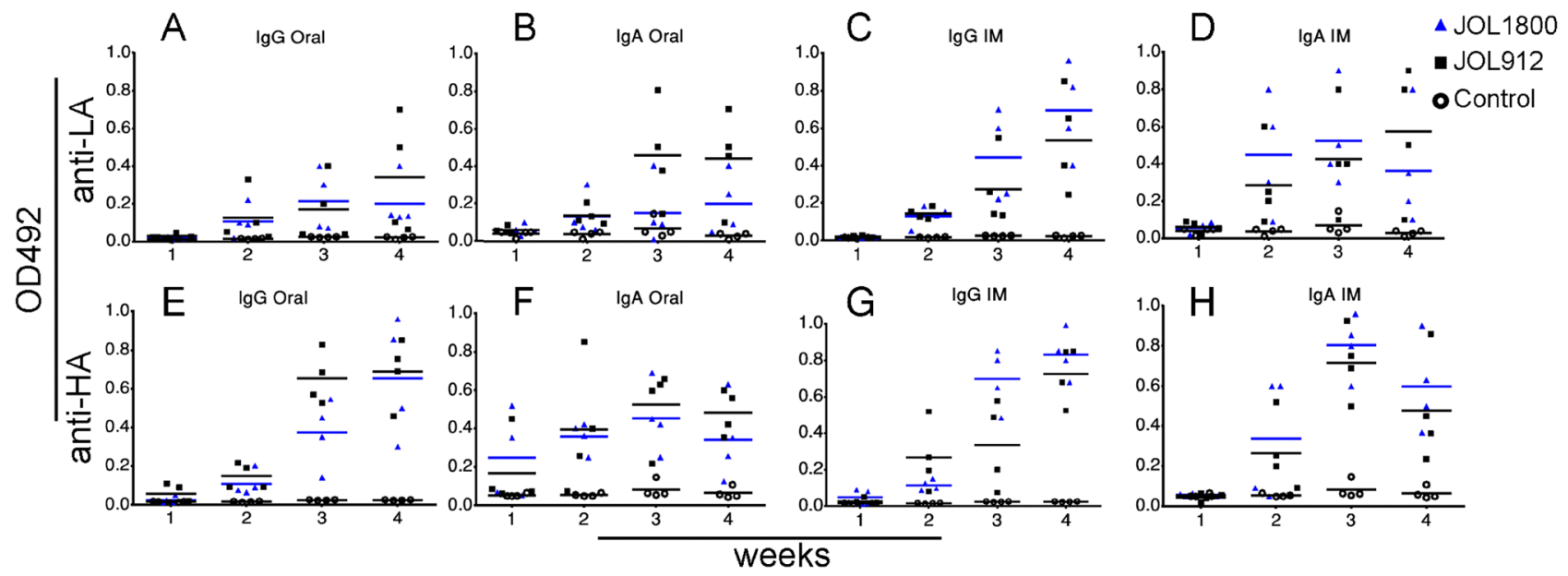

Figure 3: Humoral responses to delivered antigen. The capability and versatility of Salmonella vectors for delivering diverse bacterial/viral antigens and subsequent induction of serum IgG and intestinal IgA humoral responses were evaluated using bacterial antigen. (A) IgG response of mice groups immunized with smooth JOL912L and rough JOL1800L delivery strains delivering LA antigen via oral route. (B) IgA response of mice groups immunized with smooth JOL912L and rough JOL1800L delivery strains delivering LA antigen via oral route. (C) IgG response of mice groups immunized with JOL delivery strains delivering LA antigen via IM route. (D) IgA response of mice groups immunized with JOL delivery strains delivering LA antigen via IM route. (E) IgG response of mice groups immunized with smooth JOL912H and rough JOL1800H delivery strains delivering HA antigen via oral route. (F) IgA response of mice groups immunized with smooth JOL912H and rough JOL1800H delivery strains delivering HA antigen via oral route. (G) IgG response of mice groups immunized with JOL delivery strains delivering HA antigen via IM route. (H) IgA response of mice groups immunized with JOL delivery strains delivering HA antigen via IM route. Blue bar represent mean OD492, colored bars are used to help differentiate the groups. 
were primed with wild type ST via oral inoculation. Vector strains were used to inoculate JOL401 wild type-primed and control non-primed mice at 4 weeks post priming, when anti-LPS antibodies were at plateau. Progression of the humoral response against the smooth ST was monitored to ascertain the levels of priming induced following immunization (Figure 7). At 9 days post vectordelivery, with the establishment of infection, non-primed naive mice showed a surge in ST vector cfu (Figure 8). However, in primed mice, reduction in the cfu of smooth and rough strains vectors was observed. Further, the rough strain JOL1800 showed lower bacterial recovery, which in part may be due to the attenuation profile. However, the percent reduction in colony count was greater in the JOL912 strain. Further, a higher dose overcomes this pre-existing immune response effect, and the amount of bacteria recovered from spleens was adequate for effective antigen delivery. Further, to investigate the effects of priming on humoral and cell-mediated responses of the delivered antigens, IgG levels and lymphoproliferative index were determined on mice immunized with the JOL-delivery strains. Our data revealed that priming did not affect the humoral response against the BLS antigen delivered via rough JOL1800 (Figure 9). Further, the higher dosage of JOL1800 revealed the highest relative antibody levels. Between oral, IM, and IP routes, antigen delivered via IM showed the strongest humoral response to the delivered antigen. In this study, we also investigated the outcome of cellular immunity induced in primed and non-primed hosts. Our data revealed that the cellular immune response against delivered Brucella lumazine synthase (BLS) antigen was not affected, at least with the current experimental setup (Figure 9D). Hence, we deduced that antigen can be effectively delivered via the rough JOL1800 strain, even in a host immune-primed with natural levels of wild type smooth ST infections.
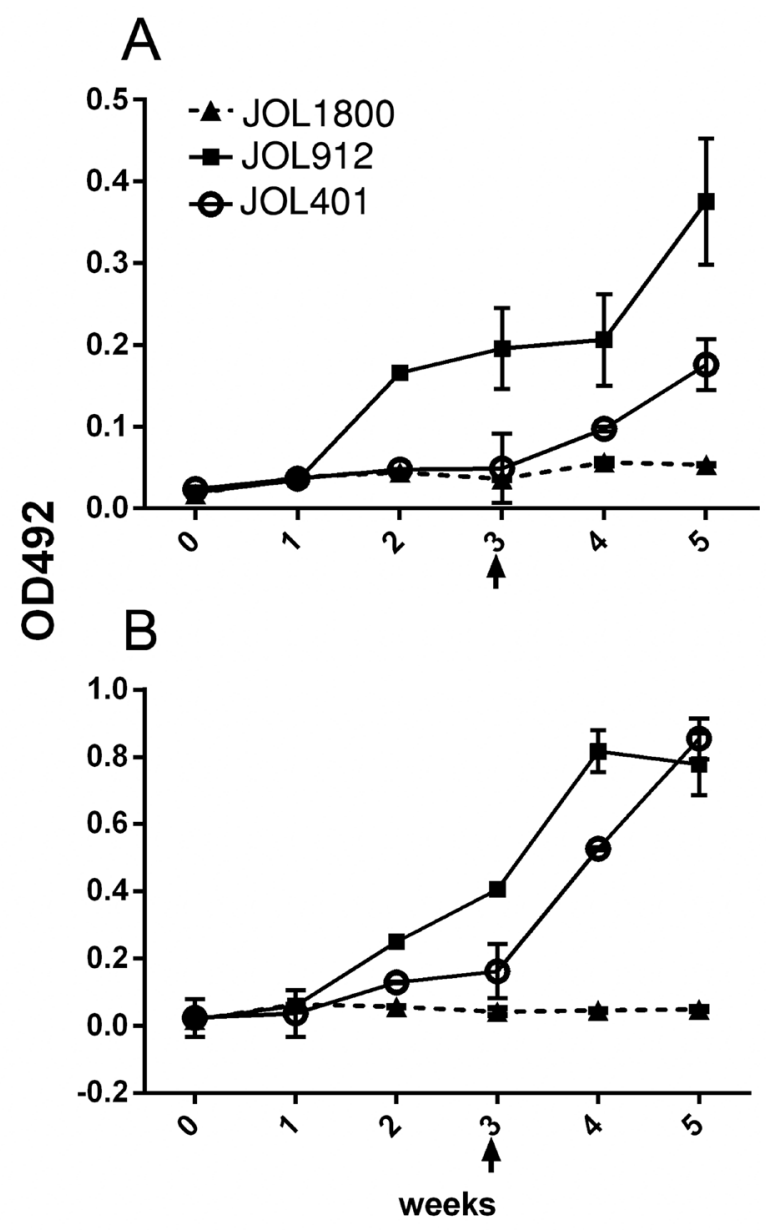

Figure 4: Assessment of DIVA capability. Mice were inoculated with the Salmonella strains to assess induction of LPS antibodies. The smooth strains JOL401 and JOL912 induced LPS specific antibodies in the inoculated mice while rough JOL1800 did not induced detectable levels. In order to rule out that JOL1800 strain might be extremely attenuated and thus is incapable of inducing any LPS specific bodies, a booster dose at the $3^{\text {rd }}$ week post inoculation was given. However, the booster dose did not further elicit the production of antiLPS antibodies which revealed the stringency of DIVA potential of the JOL1800 strain. (A) Anti-LPS IgG responses induced by oral immunization of Salmonella vector strains. (B) Anti-LPS IgG responses induced by IM immunization. Arrow depicts time point of booster immunization. 


\section{DISCUSSION}

The present study reported the generation of a suitable bacterial vector for the use in vaccine antigen delivery. However, there are certain area that needed to be address, this includes but not limited to, vector-dose optimization, inoculation route optimization, post vectordelivery protection assays, studies involving delivery of therapeutic molecules, and studies involving immunecompromise host.

Lipopolysaccharide represents the major surface antigen of gram-negative bacteria and harbors bindingsites for antibodies [37]. LPS is important in the recognition and elimination of bacteria by the host immune system $[34,38]$. In this study, the rough ST delivery strain JOL1800 was generated from a parental lon-cpxR-asd mutant ST strain via $r f a L$ gene deletion. The $r f a L$ gene (synonyms: $r f b T$, waaL) encodes for an O-antigen ligase protein involved in the LPS core biosynthesis pathway, which is part of bacterial outer membrane biogenesis [39]. Loss of $r f a L$ resulted in loss of all O-Ag side-chains (Figure 1B), while the core oligosaccharide remained intact [40]. In our previous studies, we reported that loncpxR mutant Salmonellae resulted in increased bacterial capsular polysaccharide production [19, 41], an increase in macrophage-bacterial uptake [42], and attenuation as indicated by an oral-lethal dose $50\left(\mathrm{LD}_{50}\right)$ of $4.1 \times 10^{9}$ cfu [41] and greater than $2.8 \times 10^{10} \mathrm{cfu}[42]$ in BALB/c mice and brown nick chickens, respectively. While the degree of attenuation expressed in terms of $\mathrm{LD}_{50}$ is important for determining the upper dosage limit of the vaccine-vector, studies measuring residual virulence for the purpose of antigen delivery may be more meaningful. Recovery time and residual virulence parameters express the time duration and quantity of residual bacteria present in the host system, respectively, and they represent the availability of vector for antigen production/delivery inside the host. Based on the present data, the $\mathrm{RT}_{50}$ of JOL1800 was determined to be around 5 days in both oral and IM routes. In summation, JOL1800 is highly attenuated and thus facilitates higher vector-dosing administration, and the duration and residual quantity of colonization were suitable for effective antigen delivery, as suggested by humoral and cell-mediated immune responses against the delivered antigens.

We affirmed in this report that live ST vectors can remotely activate mucosal immunity via systemic immunization, and vice versa. It was evident that live ST secretes antigen payloads at immunological active sites other than the site of immunization. This phenomenon added the advantage of using a live ST vector system, as live Salmonella bacteria may migrate to the intestinal mucosal sites post intramuscular inoculation [19]. Remote activation of the mucosal immune response is a recognized phenomenon that is also the basis of the common mucosal immune response [43, 44]. However, remote mucosal immune-activation in most cases is achievable only via mucosal immunization routes such as, oral, nasal, rectal, or vaginal [44]. Moreover, the common mucosal immune response is rather compartmentalized and localized [43]. We validate that IM immunization of LA and HA delivered by ST in mice could generate strong anti-LA and
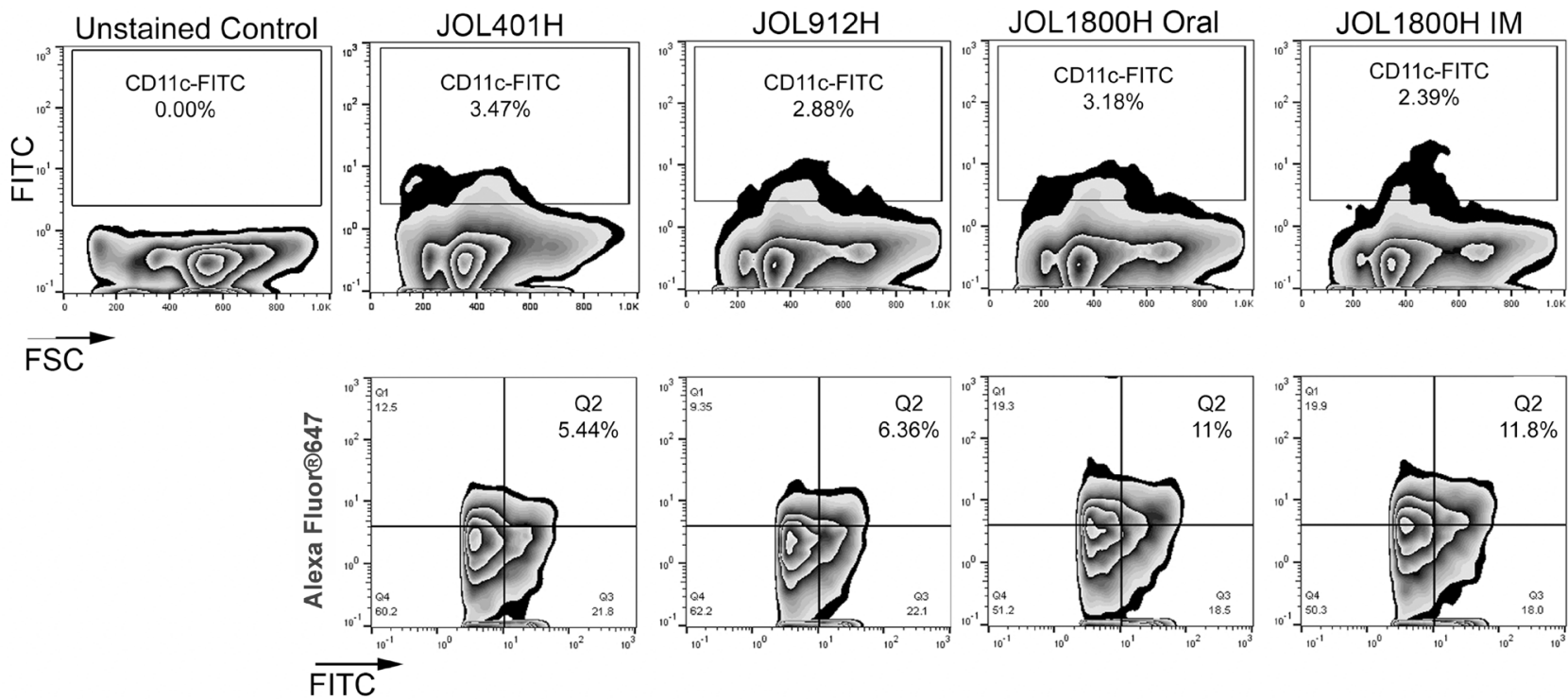

Figure 5: FACS analysis of antigen presentation. The fractions of DC presenting delivered antigen was determined on murine splenocytes using flow cytometric analysis. Mice were inoculated with hemagglutinin delivering ST strains, viz. wild type strain (JOL401H), smooth strain (JOL912H) and rough strain (JOL1800H). At 5 days post inoculation, mice were euthanized, and splenocytes were harvested aseptically and subjected to FACS analysis. DC population was gated with anti-CD11c-FITC and the delivered antigen HA protein was detected with rabbit anti-HA primary antibody and anti-rabbit IgG-AlexaFluor647. 
HA SIgA antibodies in the intestines (Figure 3), which is induced by ST operating in the MLNs of mice from where the organism is readily isolated (Figure 8).

In the present study, antigen display/presentation was determined at 5 days post-inoculation, as the number of ST present in the spleen was comparable among the inoculation mice, and the majority of the mice were ST-positive (Table 2). Based on our delivered-antigen display experiment, the number of bacteria recovered from spleens does not directly represent the amount of bacterial/bacterial-delivered antigens processed or presented by APC. Mice inoculated with the JOL401 strain exhibited the highest bacterial recovery at each time point; however, the FACS analysis did not reflect higher antigen signals from the gated CD $11 \mathrm{c}^{+} \mathrm{DCs}$ from the pool of splenocytes. In contrast, with comparative lower splenic bacterial recovery levels, the frequency of HA-positive CD11 $\mathrm{c}^{+}$DCs was elevated in the group inoculated with JOL1800 (Figure 5). The exact mechanism explaining how processing and thereby antigen display were higher in rough strain delivery is unclear; however, it may be related to inhibition of lysosomal degradation by the wild type strain [45]. While the wild type JOL401 strain evaded lytic killing and continued replication inside the ST-containing vacuoles, the deficiency of Lon protease repression in JOL912 and JOL1800 $\Delta$ lon mutants may have resulted in the induction of apoptosis [46], thereby releasing bacteria from their replicating niche. It was reported that LPS is not involved in the inhibition of phagolysosomal degradation by phagocytic cells [45], and it was reported that Salmonella strains induce delayed apoptosis dependent on SPI-2 function that requires LPS for induction [47]. Moreover, LPS is involved in the activation of lysosomeassociated membrane proteins (LAMP), particularly LAMP-3, which is important for Salmonella intracellular proliferation [48]. Hence, the absence of LPS could result in decreased activation of LAMP-3 and also decrease intracellular proliferation.

Wild type ST are intracellular pathogens that remain restricted to the endosomal compartment of eukaryotic cells, resisting nonspecific killing mechanisms [49]. However, resistance to killing by the smooth type could
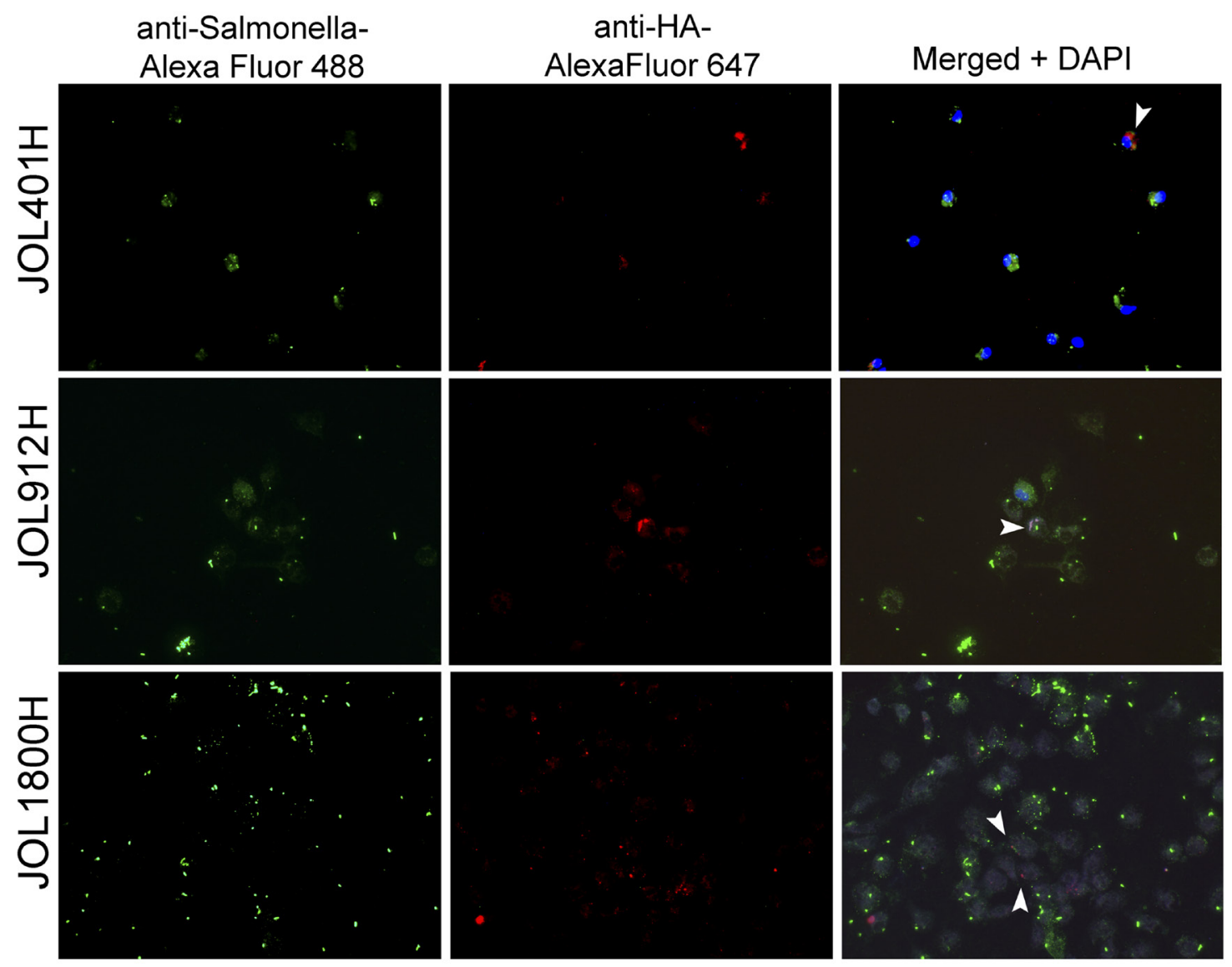

Figure 6: Fluorescence microscopic observed of delivered antigen display on mock infected macrophages. Murine intraperitoneal macrophages were infected in vitro at 10:1 MOI with hemagglutinin delivering ST strains, viz. wild type strain (JOL401H), smooth strain (JOL912H) and rough strain $(\mathrm{JOL} 1800 \mathrm{H})$. At $16 \mathrm{hr}$ post infection, the cells were fixed and subjected to immunofluorescence microscopic analysis. Macrophages infected with JOL1800H showed maximal display of Salmonella and HA antigens which was followed by JOL912H. Arrowhead depicts HA antigen bound fluorescence signal (red) on the surface of macrophage; Magnification- 200X. 
result in minimal processing of the antigen payload. Hence, the vector component should be readily taken up and processed. One concern with the use of ST strains as a vaccine carrier expressing heterologous antigens is the effect of introduction into immunized hosts or the repeated use of the organism [50]. Thus, whether preexisting immunity interferes with the subsequent use of live ST vaccine vectors may depend on timing and the genetic characteristics and immunogenicity of the strain. With the appropriate vaccine strain, preexisting immunity should not preclude the reuse of carriers or their use in areas where individuals have been previously exposed to Salmonellae [50]. In addition, some findings suggest that ST vaccine vectors cannot be employed to deliver multiple doses of a vaccine antigen [51]. It is likely that the replication and spread of the bacteria were curtailed by the presence of residual LPS antibodies and immunological memory due to the first immunization [51]. We anticipated that removal of immunodominant LPS from the vector would minimize immune recognition and bacterial clearance in wild type- primed host. In the present study, mice were primed with wild type ST to mimic natural infection and to induce preexisting immunity. As it would occur in nature, smooth strain JOL401 was inoculated orally for this purpose. The levels of anti-LPS and anti-OMP antibodies were monitored on a weekly basis using ELISA. Also, BLSspecific lymphoproliferative responses were measured at 21 days post-priming (Figure 9D), and ST vectors were inoculated at 4 weeks post priming. At 9 days postinoculation, a reduction in all strains due to the immune response was observed in primed mice (Figure 8). The number of bacteria recovered from the spleen was lower for the rough JOL1800 strain as compared to JOL912, this finding is anticipated as JOL1800 is more attenuated than JOL912. However, considering the degree of reduction using non-primed mice as a reference, the smooth strain JOL912 was more affected by priming and prior exposure to the smooth wild type strain. The observed phenomenon may be, in part, due to anti-LPS immune responses in mice.

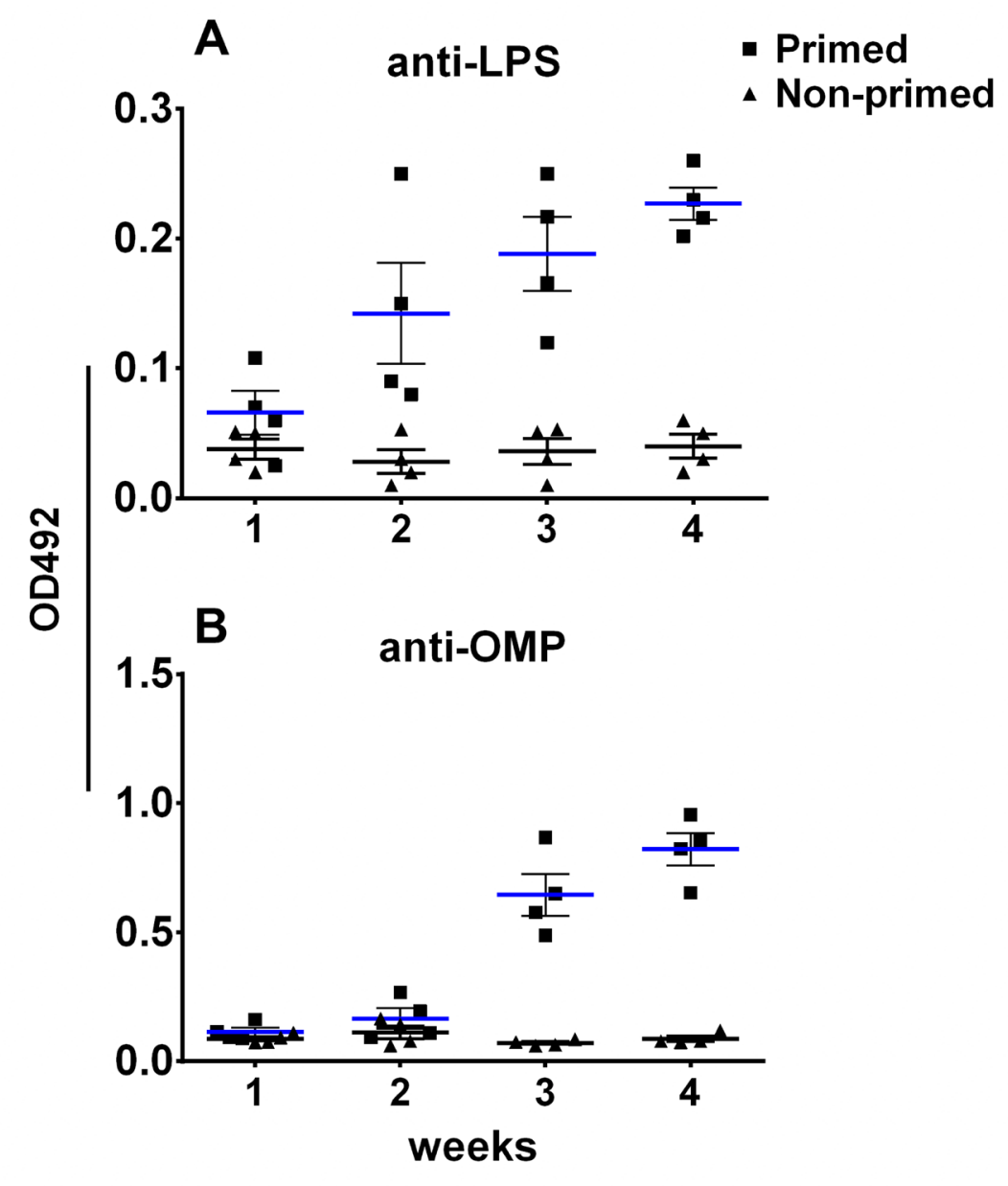

Figure 7: Immune priming of mice with live Salmonella. The effect of priming with Salmonella on the humoral immune response following oral inoculation was monitored. (A) Production of anti-LPS IgG in primed versus non-primed mice. (B) Production of anti-OMP $\mathrm{IgG}$ in primed versus non-primed mice. Blue bar represents mean titre for primed mice; black bar represents mean titre for non-primed mice. 
Taken together, our data support that the JOL1800 rough ST delivery vector is adequately attenuated to permit high-dosage deployment and ideally resides in the host system long enough to achieve the required immune response. We also demonstrated that the rough JOL1800 phenotype assisted in enhanced-antigen presentation and processing of the delivered antigen. Removal of O-Ag from the strain also assisted in avoiding wild type preexisting immunity. In addition, Salmonella serotyping is conventionally performed based on seroreactivity against $\mathrm{O}-\mathrm{Ag}$; in primed hosts, the major anti-Salmonella antibody is generated against O-Ag, deployment of JOL1800 delivery in the livestock sector will not interfere with LPS-based Salmonella Typhimurium diagnostics and serotyping, as JOL1800 is DIVA-enabled. These findings suggest that rough JOL1800 can be used for safe and efficient antigen delivery.

\section{MATERIALS AND METHODS}

\section{Animals and ethics statement}

All animal experimental procedures were approved (CBNU2015-00085) by the Chonbuk National
University Animal Ethics Committee in accordance with the guidelines of the Korean Council on Animal Care and Korean Animal Protection Law, 2007; Article 13 (experiments with animals). All animals were purchased from Koatech (Pyeongtaek, Gyeonggi-do, Korea). All female animals were used for the study; two New Zealand white rabbits (8-9 weeks age) and specific pathogen-free BALB/c inbred mice (4-5 weeks average age) were kept under air-conditioned rooms, maintained humanely and were provided water and antibiotic-free food ad libitum. Rabbits were housed 1 animal per cage and mice were housed at 5 animals per cage. Animals were monitored twice daily for behavioral and physiological signs. During blood sample collections, rabbits were secured with large cloth to avoid inadvertent movements. After wiping with xylene and alcohol swabs, approximately 4-5ml blood is drawn from the marginal ear vein. At the end of serum complement harvesting, the rabbits were released back to rabbit farm. At the completion or end point of experiments, mice were euthanized by cervical dislocation strictly following standard procedures. All efforts were made to ensure humane handling of animals and to minimize animals suffering.

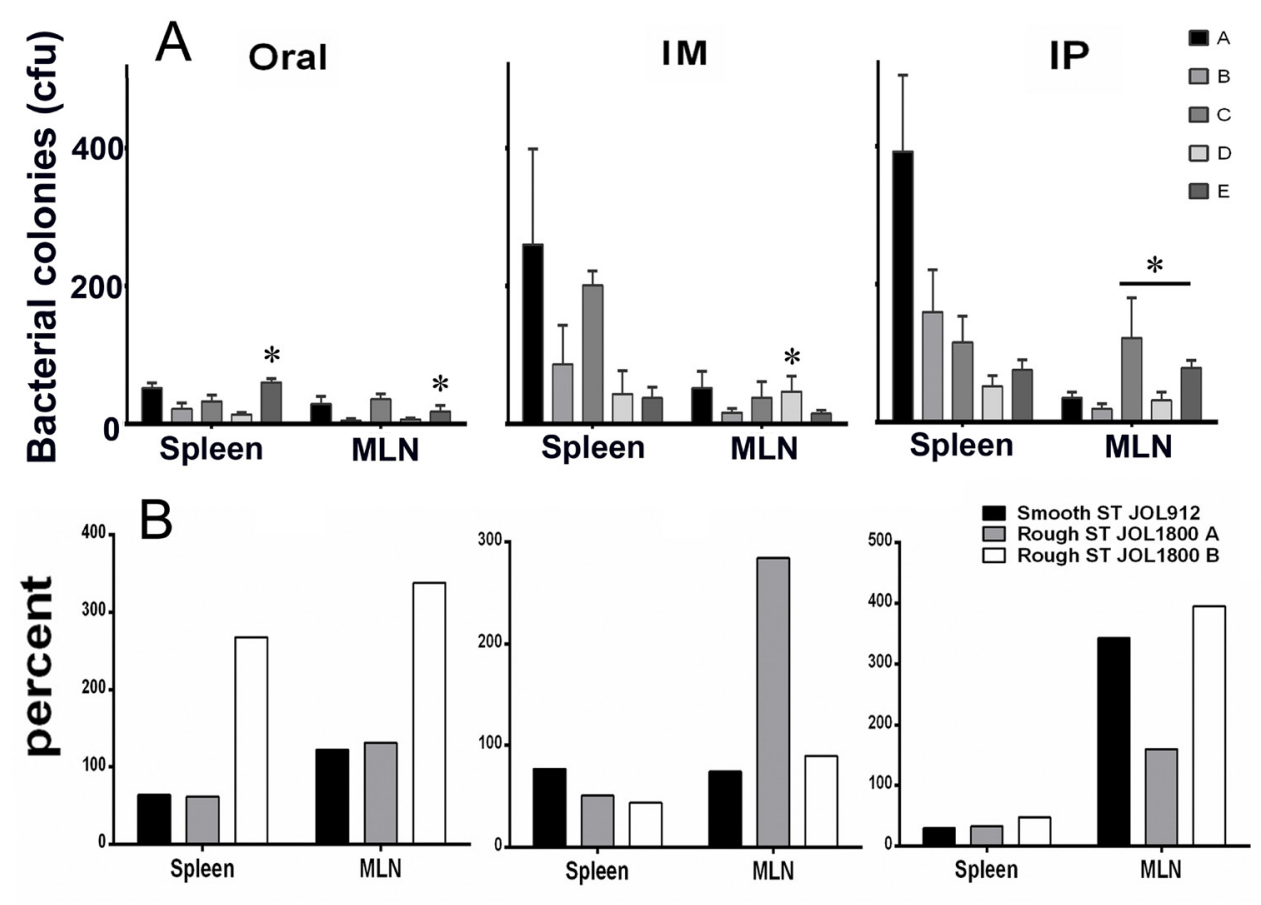

Figure 8: Effects of priming on colonization of rough and smooth Salmonella. The fate of vector vaccine inside host harboring pre-existing Salmonella immunity was investigated. To simulate natural infection, mice were inoculated orally with smooth wild type ST strain. Effects of priming on colonization of vector in spleen and mesenteric lymph nodes (MLN). (A) Bacterial recovery of Salmonella vector strains from primed and non-primed mice. Group A and B- non primed, group C-E- primed; group A and C- inoculated with smooth JOL912 $\left(2 \times 10^{6} \mathrm{cfu}\right)$, group B and D- inoculated with rough JOL1800 $\left(2 \times 10^{6} \mathrm{cfu}\right)$; group E- inoculated with rough JOL1800 $\left(1 \times 10^{8}\right.$ cfu). "indicates significant difference $(P \leq 0.05)$ as compared to corresponding non-primed controls group A or B. (B) Percent fraction of vector strain recovered from primed mice. The percentage was calculated as- (mean vector CFU recovered from primed mice divided by mean vector CFU recovered from un-primed mice) $\times 100$. ST- Salmonella Typhimurium; JOL1800 A- $2 \times 10^{6}$ cfu vector dose; JOL1800 B- $2 \times 10^{8}$ cfu vector dose. 


\section{Bacterial strains, plasmids, and primers}

Bacterial strains used in this study are described in Table 1. The aspartate $\beta$-semialdehyde dehydrogenase (asd) gene-deleted Salmonella enterica serovar Typhimurium (ST) strains were grown at $37^{\circ} \mathrm{C}$ in lysogeny broth (LB) containing $50 \mu \mathrm{g} / \mathrm{ml}$ diaminopimelic acid. Temperaturesensitive bacterial strains were grown at $28^{\circ} \mathrm{C}$ in LB broth. For induction of red lambda genes, strains were induced in LB broth containing $0.2 \% \mathrm{~L}$-arabinose. Bacterial strains were stored as frozen cultures in LB broth containing $20 \%$ glycerol at $-80^{\circ} \mathrm{C}$ until use.

\section{Construction and characterization of a live ST bacterial vector}

The knock out mutant strain was constructed per the previously described protocol [52]. Briefly, prior to the target gene deletion from the host strain, JOL912 was electroporated with the helper plasmid pKD46, which provides the inducible red lambda components required for recombination. The target gene $r f a L$ was replaced with the $c a t^{R}$ gene contained on a linear PCR product amplified from the pkD3 plasmid. Recombinant clones were selected by plating on LB broth containing $25 \mu \mathrm{g} /$ $\mathrm{ml}$ chloramphenicol. The knockout event was confirmed using outer and inner PCR primers. Finally, the antibiotic resistance cassette was eliminated using the helper plasmid pCP20. The PCR primers used for construction are listed in Table 1.

SDS-PAGE and silver staining demonstrated validation of the rough phenotype. For this purpose, LPS was extracted using a phenol-based commercial LPS extraction kit (iNtRON Biotechnology, South Korea). Purified LPS was electrophoresed on 15\% PAGE gels; after fixation, the gel was stained using a silver staining kit
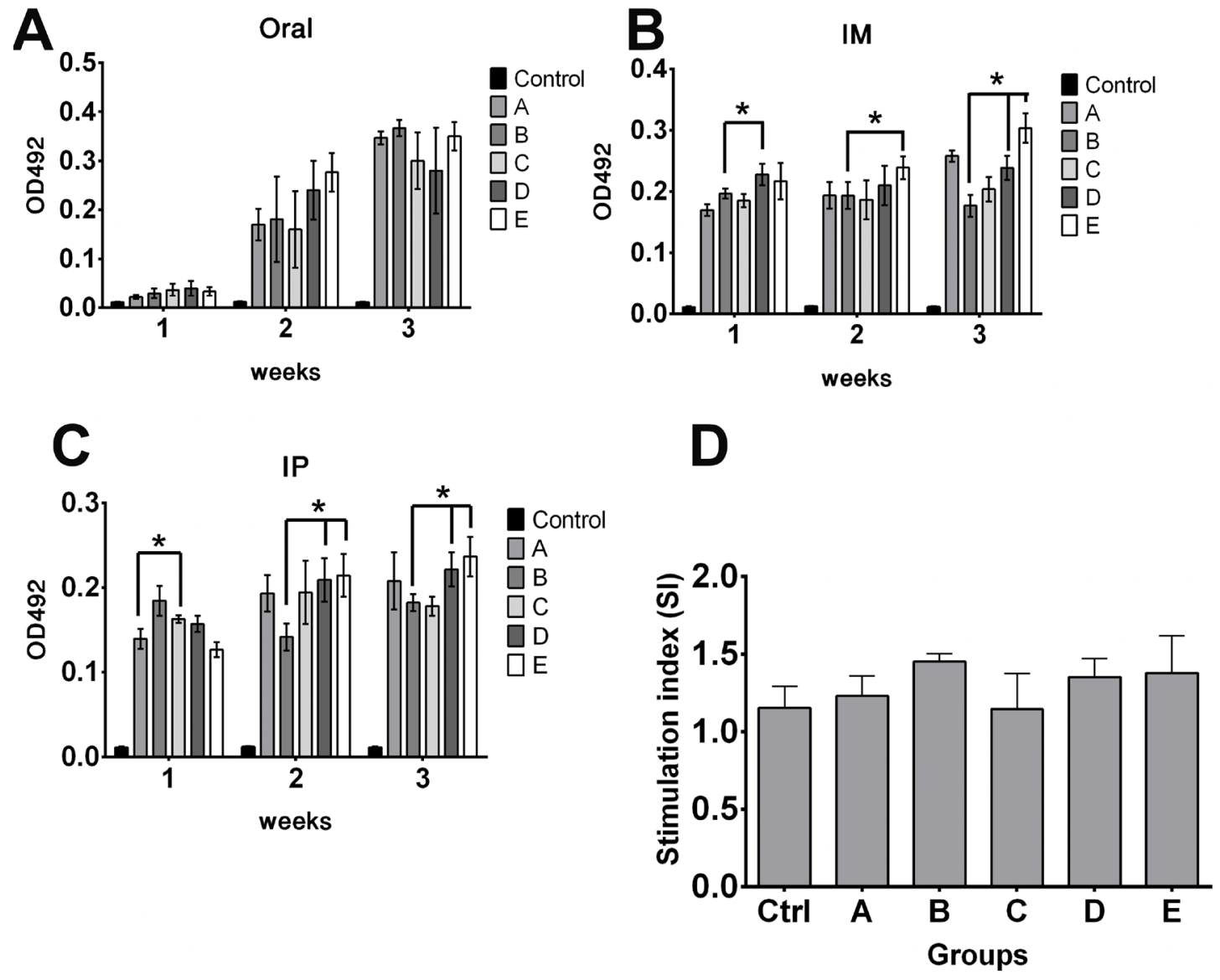

Figure 9: Effects of priming on antigen delivery. The fate of delivered antigen (Brucella lumazine synthase) inside host harboring pre-existing Salmonella immunity was investigated. To simulate natural infection, mice were inoculated with smooth wild type ST strain. Effects of priming on humoral and cellular immune responses of delivered antigen in primed and non-primed mice were determined. (A) Effects of priming on IgG responses following oral delivery. (B) Effects of priming on IgG responses following IM delivery. (C) Effects of priming on IgG responses following IP delivery. Control group represents naive mice anti-BLS IgG levels. (D) Effects of priming on splenocytes proliferation responses following IM delivery. Cellular immune response against delivered Brucella lumazine synthase (BLS) antigen was not decreased. *indicates significant difference $(P \leq 0.05)$ as compared to corresponding non-primed controls group A or B. Group A and B- non primed, group C-E- primed; group A and C- inoculated with smooth JOL912 $\left(2 \times 10^{6}\right.$ cfu $)$, group B and D- inoculated with rough JOL1800 $\left(2 \times 10^{6} \mathrm{cfu}\right)$; group E- inoculated with rough JOL1800 $\left(1 \times 10^{8} \mathrm{cfu}\right)$. 
(Silver Stain Plus, Bio-Rad, USA). An LPS oxidation step using $200 \mu \mathrm{L}$ of periodic acid $(20 \% \mathrm{w} / \mathrm{v})$ was included in the staining process.

\section{In vitro complement sensitivity assay}

The serum complement sensitivity of ST strains was ascertained with naive rabbit serum, using protocol described earlier [53]. Fresh serum, negative of antiST antibody was collected from rabbits and used for the assay. All bacterial strains were grown to late log phase, and $1 \times 10^{3} \mathrm{cfu} / 100 \mu 1$ each of JOL401, JOL912, and JOL1800 cultures were incubated separately with

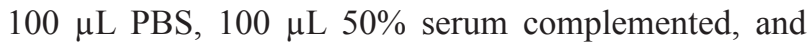
$100 \mu \mathrm{L}$ de-complemented serum for $1 \mathrm{~h}$ at $37^{\circ} \mathrm{C}$. After incubation, each of the test lots was plated onto respective LB agar plates with or without 2,6-diaminopimelic acid supplementation. The data are represented as the mean percent of inoculum $=\left(\mathrm{CFU}_{\text {treatment }} / \mathrm{CFU}_{\mathrm{PBS}}\right) \times 100$.

\section{Recovery of ST strains}

A total of 128 mice were divided equally into four groups $(n=32)$. At 4 weeks of age, the mice were inoculated with $1 \times 10^{7} \mathrm{cfu}$ of JOL401, JOL912, and JOL1800 strains orally, and the fourth group was inoculated with $1 \times 10^{7} \mathrm{cfu}$ of JOL1800 intramuscularly (IM). For the purpose of this experiment, $\Delta$ asd strains JOL912 and JOL1800 were electro-transformed with the asd $^{+}$plasmid pJHL65. At days 3, 7, 14, and 21 post inoculation, eight mice from each group were euthanized by cervical dislocation, and splenic samples were collected. To determine the presence of ST strains in the spleens, the organ was homogenized in $2 \mathrm{~mL}$ buffered peptone water (BPW, Becton, MD, USA). One hundred $\mu \mathrm{L}$ homogenate was directly inoculated and spread on brilliant green agar plates (BGA) and incubated overnight at $37^{\circ} \mathrm{C}$. In parallel, the remaining BPW samples were further enriched with Rappaport-Vassiliadis (RV) broth by incubation at $37^{\circ} \mathrm{C}$ for $48 \mathrm{~h}$. The ST-like colonies obtained were finally confirmed by PCR using ST specific primers [54]. The $\mathrm{RT}_{50}$ of ST strains was determined using the graphical statistical method described earlier [55-57].

\section{Humoral immune response against delivered antigens}

A total of 80 mice were equally divided into eight groups $(n=10)$. All mice were inoculated at 4 weeks of age with smooth or rough strains delivering Lawsonia autotransporter protein A (LA) or hemagglutinin from H1N1 (HA); JOL912L, JOL912H, JOL1800L, or JOL1800H strains, either orally or IM with $10^{7}$ and $10^{6} \mathrm{cfu}$ in $100 \mu \mathrm{L}$ volume, respectively. Naïve un-inoculated mice $(n=6)$ were also maintained to serve as a reference control. Serum and intestinal lavage samples were collected at weekly intervals for 5 weeks post inoculation. Indirect ELISA was conducted as per protocol described previously [25] using purified LA and HA recombinant proteins. Briefly, $500 \mathrm{ng} / \mathrm{well}$ of antigens was used for coating ELISA plates (MaxiSorp, NUNC). Primary mouse serum and SIgA samples were diluted at 1:100 and 1:5 with PBS, respectively, and secondary HRP-conjugated anti-mice IgG and IgA antibody were used at concentrations of 1:8000 and 1:5000 dilutions, respectively. Colorimetric changes due to HRP acting on OPD (Sigma-Aldrich, USA) were measured after $5 \mathrm{~min}$ at $492 \mathrm{~nm}$ (TECAN, Austria). The values for $\operatorname{IgG}$ and IgA binding to respective antigens are expressed as the mean $\mathrm{OD}$ value $\pm \mathrm{SE}$.

\section{Quantification and direct visualization of infected cells-antigen display of delivered antigens}

The fraction of mice CD11 $\mathrm{c}^{+}$DCs displaying the delivered antigen after in vivo inoculation with ST vector was estimated. A total of 32 mice were divided equally into four groups. At 4 weeks of age, mice were inoculated with $10^{7} \mathrm{cfu} / 100 \mu \mathrm{L}$ of JOL $401 \mathrm{H}$ or JOL912H via IM, or JOL1800H via oral as well as IM. At 5 days post inoculation, mice were euthanized, and splenocytes were harvested aseptically and subjected to FACS analysis. For the detection of DCs and the displayed antigen, $10^{6}$ splenocytes were stained with anti-mouse CD11c-FITC antibodies (Miltenyi Biotec, Germany). The displayed HA antigen was detected using primary rabbit anti-HA antibody (GenScript, USA) at a 1:1000 dilution; Anti-HA polyclonal antibody was used for the experiment in order to detect diverse range of HA peptides presented on the surface of CD11c+ cells. For secondary antibody, goat anti-rabbit IgG H\&L conjugated with Alexa Fluor ${ }^{\circledR 647}$ was used at a 1:2000 dilution (Abcam, UK). Relevant isotype controls, internal controls, and unstained cell controls were kept. The splenocyte populations that were positive for CD11c and HA were enumerated, and the mean percent \pm SEM was determined.

The frequency of antigens displayed by individual primary intraperitoneal (IP) macrophages after in vitro infection with ST vector was ascertained by direct observation following immunofluorescence staining. Primary IP macrophages were harvested from 4-weekold mice following IP inoculation of 5\% bovine serum albumen. Macrophages were harvested aseptically and seeded as $5 \times 10^{6}$ cells on $0.2 \%$ gelatin-coated glass cover slips that were housed in 6-well cell culture plates containing RPMI-1640 medium (Gibco, USA). After $24 \mathrm{~h}$ of culturing at $37^{\circ} \mathrm{C}$ in a $5 \% \mathrm{CO}_{2}$ atmosphere, the macrophages were infected with JOL401H, JOL912H, or JOL1800H ST vectors delivering HA antigen at an MOI of 10:1. Infection was initiated by brief centrifugation, and the culture plate was incubated at $37^{\circ} \mathrm{C}$ in a $5 \% \mathrm{CO}_{2}$ atmosphere for $30 \mathrm{~min}$. Non-internalized bacteria were 
washed with PBS, and the cells were further incubated with antibiotics containing RPMI for $48 \mathrm{~h}$. Cells on the coverslips were fixed with $2 \%$ paraformaldehyde and subjected to immunofluorescence staining. ST bacteria were stained with primary chicken anti-Salmonella hyperimmune serum (1:1000) and secondary goat anti-chicken IgY H\&L-

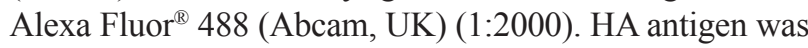
detected using primary rabbit anti-HA antibody (GenScript, USA) at a 1:1000 dilution and secondary goat anti-rabbit IgG H\&L-Alexa Fluor $^{\circledR} 647$ at a 1:2000 dilution (Abcam, UK). Macrophage nuclei were counterstained with 2-(4-amidinophenyl)-1H -indole-6-carboxamidine (DAPI; Sigma-Aldrich, USA) at a $0.5 \mu \mathrm{g} / \mathrm{mL}$ final concentration. The cover-slips were retrieved from the wells, attached to a micro-slide, and then observed under a fluorescence microscope (AX1 Zeiss, Germany).

\section{Serum IgG-based DIVA capability assessment}

A total of 60 mice were equally divided into six groups $(n=10)$. All mice were inoculated at 4 weeks of age, followed by a second dose 3 weeks post inoculation. Mice were inoculated with JOL401, JOL912, or JOL1800 strains, either orally or IM with $1 \times 10^{7}$ and $1 \times 10^{6} \mathrm{cfu}$ in $100 \mu \mathrm{L}$ volume, respectively. Serum samples were collected from 4 mice at weekly intervals for 5 weeks post inoculation. LPS-indirect ELISA was conducted using purified Salmonella Typhimurium LPS (L6511 SIGMA, Sigma-Aldrich Co. LLC, USA). Briefly, 500 ng/well of LPS was used for coating ELISA plates (MaxiSorp, NUNC). Primary mice serum was diluted at 1:100 with PBS, and secondary HRP conjugated anti-mice IgG antibody was used at a 1:8000 dilution. Colorimetric changes due to HRP acting on OPD (Sigma-Aldrich, USA) were measured after $5 \mathrm{~min}$ at $492 \mathrm{~nm}$ (TECAN, Austria). The values for serum IgG binding to LPS are expressed as the mean $\mathrm{OD}$ value $\pm \mathrm{SE}$.

\section{Effects of pre-existing immunity on ST vector colonization and efficacy of antigen delivery}

A total of 90 mice were equally divided into five groups $(n=18)$. Group A and Group B were comprised of non-primed mice. At 4 weeks of age, Groups C, D, and E were primed with smooth wild type JOL401 at $10^{5} \mathrm{cfu} /$ mouse via oral inoculation. Serum samples were collected weekly until 4 weeks post priming $(n=4)$ to ascertain humoral responses to priming. Anti-LPS and anti-outer membrane protein $\mathrm{IgG}$ responses after oral inoculation was monitored on the serum samples using indirectELISA as per protocol described elsewhere [26]. Briefly, $600 \mathrm{ng}$ of Omp/well or $500 \mathrm{ng}$ of purified ST- LPS (L6511 SIGMA, Sigma-Aldrich Co. LLC, USA) /well was used to coat ELISA plates (Maxisorp, NUNC). Primary mouse sera were diluted with PBS at 1:100 dilutions. Secondary horseradish peroxidase (HRP)-conjugated anti-mice IgG antibodies were used at 1:5000 dilutions. Colorimetric changes resulting from the action of HRP on OPD (SigmaAldrich, US) were measured (TECAN, Austria) at $492 \mathrm{~nm}$, 10 post-development. The values for binding of IgG to respective antigens was expressed as the mean OD value \pm standard error of mean (SEM). Cellular immunity induced by priming was also ascertained 4 weeks post priming $(n=4)$. To deliver Brucella lumazine synthase (BLS) via JOL strains, the mice groups were inoculated with $2 \times 10^{6}$ cfu of JOL912B (Groups A and C), JOL1800B (Groups B and D), and Group E mice were inoculated with $1 \times 10^{8} \mathrm{cfu}$ JOL $1800 \mathrm{~B}$ at 5 weeks post priming via oral, IM, and IP routes. The degrees of splenic and mesenteric lymph node (MLN) colonization and clearance in non-primed and primed mice were ascertained at 9 days post-delivery inoculation. To differentiate wild type and vector strains, chloramphenicol resistance plasmid was introduced in vector strains and selected accordingly. Bacterial recovery and enumeration were performed per the protocol described above. The percentage of cfu recovered from primed mice as compared to non-primed mice was ascertained. Serum samples were collected at weekly intervals for 3 weeks post-delivery $(n=6)$. Outer membrane (OMP)-, LPS-, and BLS-indirect ELISA were conducted using purified Salmonella Typhimurium OMP antigen, LPS (L6511 SIGMA, Sigma-Aldrich Co. LLC, USA), and recombinant BLS protein, respectively, on collected serum samples. Lymphoproliferative assays against purified recombinant BLS protein were conducted in the splenocytes of mice pre and post priming $(n=6)$.

\section{Statistical analysis}

Statistical analyses were performed wherever applicable. One-way analysis of variance (ANOVA) and Student's $t$-tests were used to determine statistically significant differences, with a $P$ value $\leq 0.05$ considered significant. Tukey's test was applied for post hoc analysis. Analyses were performed using SPSS 16.0 (SPSS Inc., Chicago, IL, USA).

\section{Author contributions}

J.L. \& J.H.L. conceived and designed the experiments. J.L. \& K.J.H performed the experiments. J.L. \& J.H.L. analyzed the data and wrote the manuscript. All the authors discussed the results and commented on the manuscript.

\section{ACKNOWLEDGMENTS}

This research was supported by a grant of the Korea Health Technology R\&D Project through the Korea Health Industry Development Institute (KHIDI), funded by the Ministry of Health \& Welfare, Republic of Korea (grant number: HI16C2130). 


\section{CONFLICTS OF INTEREST}

The authors declare no competing financial interests.

\section{REFERENCES}

1. Piñero-Lambea C, Ruano-Gallego D, Fernández LÁ. Engineered bacteria as therapeutic agents. Curr Opin Biotechnol. 2015; 35:94-102. https://doi.org/10.1016/j. copbio.2015.05.004.

2. Kotton CN, Hohmann EL. Enteric pathogens as vaccine vectors for foreign antigen delivery. Infect Immun. 2004; 72:5535-47. https://doi.org/10.1128/IAI.72.10.5535-5547.2004.

3. Camacho EM, Mesa-Pereira B, Medina C, Flores A, Santero E. Engineering Salmonella as intracellular factory for effective killing of tumour cells. Sci Rep. 2016; 6:30591. https://doi.org/10.1038/srep30591.

4. Méresse S, Steele-Mortimer O, Moreno E, Desjardins M, Finlay B, Gorvel JP. Controlling the maturation of pathogencontaining vacuoles: a matter of life and death. Nat Cell Biol. 1999; 1:E183-88. https://doi.org/10.1038/15620.

5. Hoiseth SK, Stocker BA. Aromatic-dependent Salmonella typhimurium are non-virulent and effective as live vaccines. Nature. 1981; 291:238-39. https://doi.org/10.1038/291238a0.

6. Curtiss R 3rd, Kelly SM. Salmonella typhimurium deletion mutants lacking adenylate cyclase and cyclic AMP receptor protein are avirulent and immunogenic. Infect Immun. 1987; 55:3035-43.

7. Galán JE, Curtiss $\mathrm{R}$ 3rd. Virulence and vaccine potential of phoP mutants of Salmonella typhimurium. Microb Pathog. 1989; 6:433-43. https://doi. org/10.1016/0882-4010(89)90085-5.

8. Dunne M, al-Ramadi BK, Barthold SW, Flavell RA, Fikrig E. Oral vaccination with an attenuated Salmonella typhimurium strain expressing Borrelia burgdorferi OspA prevents murine Lyme borreliosis. Infect Immun. 1995; 63:1611-14.

9. Kim WK, Moon JY, Kim S, Hur J. Comparison between immunization routes of live attenuated Salmonella typhimurium strains expressing BCSP31, Omp3b, and SOD of Brucella abortus in murine model. Front Microbiol. 2016; 7:550. https://doi.org/10.3389/fmicb.2016.00550.

10. Nardelli-Haefliger D, Roden RB, Benyacoub J, Sahli R, Kraehenbuhl JP, Schiller JT, Lachat P, Potts A, De Grandi P. Human papillomavirus type 16 virus-like particles expressed in attenuated Salmonella typhimurium elicit mucosal and systemic neutralizing antibodies in mice. Infect Immun. 1997; 65:3328-36.

11. Karem KL, Bowen J, Kuklin N, Rouse BT. Protective immunity against herpes simplex virus (HSV) type 1 following oral administration of recombinant Salmonella typhimurium vaccine strains expressing HSV antigens. J Gen Virol. 1997; 78:427-34. https://doi.org/10.1099/0022-1317-78-2-427.

12. Chacón MR, Londoño P, Dougan G, Selkirk ME. Heterologous expression of the cuticular-glutathione peroxidase of lymphatic filariae in an attenuated vaccine strain of Salmonella typhimurium abrogates $\mathrm{H}-2$ restriction of specific antibody responses. Parasite Immunol. 1996; 18:307-16. https://doi. org/10.1046/j.1365-3024.1996.d01-105.x.

13. Sadoff JC, Ballou WR, Baron LS, Majarian WR, Brey RN, Hockmeyer WT, Young JF, Cryz SJ, Ou J, Lowell GH. Oral Salmonella typhimurium vaccine expressing circumsporozoite protein protects against malaria. Science. 1988; 240:336-38. https://doi.org/10.1126/science.3281260.

14. Schorr J, Knapp B, Hundt E, Küpper HA, Amann E. Surface expression of malarial antigens in Salmonella typhimurium: induction of serum antibody response upon oral vaccination of mice. Vaccine. 1991; 9:675-81. https:// doi.org/10.1016/0264-410X(91)90194-B.

15. Medina E, Guzmán CA, Staendner LH, Colombo MP, Paglia P. Salmonella vaccine carrier strains: effective delivery system to trigger anti-tumor immunity by oral route. Eur J Immunol. 1999; 29:693-99. https://doi. org/10.1002/(SICI)1521-4141(199902)29:02<693::AIDIMMU693>3.0.CO;2-V.

16. Wall DM, Srikanth CV, McCormick BA. Targeting tumors with salmonella Typhimurium- potential for therapy. Oncotarget. 2010; 1:721-28. https://doi.org/10.18632/ oncotarget.206.

17. Medina E, Guzmán CA. Use of live bacterial vaccine vectors for antigen delivery: potential and limitations. Vaccine. 2001; 19:1573-80. https://doi.org/10.1016/ S0264-410X(00)00354-6.

18. Matsuda K, Chaudhari AA, Lee JH. Evaluation of safety and protection efficacy on cpxR and lon deleted mutant of Salmonella Gallinarum as a live vaccine candidate for fowl typhoid. Vaccine. 2011; 29:668-74. https://doi. org/10.1016/j.vaccine.2010.11.039.

19. Lalsiamthara J, Lee JH. Virulence Associated GenesDeleted Salmonella Montevideo Is Attenuated, Highly Immunogenic and Confers Protection against Virulent Challenge in Chickens. Front Microbiol. 2016; 7:1634. https://doi.org/10.3389/fmicb.2016.01634.

20. Lalsiamthara J, Gogia N, Goswami TK, Singh RK, Chaudhuri P. Intermediate rough Brucella abortus S19 $\Delta$ per mutant is DIVA enable, safe to pregnant guinea pigs and confers protection to mice. Vaccine. 2015; 33:2577-83. https://doi.org/10.1016/j.vaccine.2015.04.004.

21. Leyman B, Boyen F, Van Parys A, Verbrugghe E, Haesebrouck F, Pasmans F. Salmonella Typhimurium LPS mutations for use in vaccines allowing differentiation of infected and vaccinated pigs. Vaccine. 2011; 29:3679-85. https://doi.org/10.1016/j.vaccine.2011.03.004.

22. Dlabac V, Trebichavský I, Reháková Z, Hofmanová B, Splíchal I, Cukrowska B. Pathogenicity and protective effect of rough mutants of Salmonella species in germ-free piglets. Infect Immun. 1997; 65:5238-43.

23. Nagy G, Dobrindt U, Hacker J, Emödy L. Oral immunization with an rfaH mutant elicits protection against 
salmonellosis in mice. Infect Immun. 2004; 72:4297-301. https://doi.org/10.1128/IAI.72.7.4297-4301.2004.

24. Kong Q, Yang J, Liu Q, Alamuri P, Roland KL, Curtiss R 3rd. Effect of deletion of genes involved in lipopolysaccharide core and O-antigen synthesis on virulence and immunogenicity of Salmonella enterica serovar typhimurium. Infect Immun. 2011; 79:4227-39. https://doi.org/10.1128/ IAI.05398-11.

25. Lalsiamthara J, Lee JH. Brucella lipopolysaccharide reinforced Salmonella delivering Brucella immunogens protects mice against virulent challenge. Vet Microbiol. 2017; 205:84-91. https://doi.org/10.1016/j. vetmic.2017.05.012.

26. Lalsiamthara J, Lee JH. Immuno-profiles of BALB/c mice inoculated with Salmonella vector delivering B-cell mitogen hydroxyproline epimerase. Mol Immunol. 2018; 95:114-21. https://doi.org/10.1016/j.molimm.2018.02.004.

27. Lalsiamthara J, Kamble NM, Lee JH. A live attenuated Salmonella Enteritidis secreting detoxified heat labile toxin enhances mucosal immunity and confers protection against wild-type challenge in chickens. Vet Res (Faisalabad). 2016; 47:60. https://doi.org/10.1186/s13567-016-0348-7.

28. Zenk SF, Jantsch J, Hensel M. Role of Salmonella enterica lipopolysaccharide in activation of dendritic cell functions and bacterial containment. J Immunol. 2009; 183: 2697-707. https://doi.org/10.4049/jimmunol.0900937.

29. Attridge SR, Davies R, LaBrooy JT. Oral delivery of foreign antigens by attenuated Salmonella: consequences of prior exposure to the vector strain. Vaccine. 1997; 15:155-62. https://doi.org/10.1016/S0264-410X(96)00158-2.

30. Saxena M, Van TT, Baird FJ, Coloe PJ, Smooker PM. Preexisting immunity against vaccine vectors - friend or foe? Microbiology. 2013; 159:1-11. https://doi.org/10.1099/ mic.0.049601-0.

31. Belyakov IM, Moss B, Strober W, Berzofsky JA. Mucosal vaccination overcomes the barrier to recombinant vaccinia immunization caused by preexisting poxvirus immunity. Proc Natl Acad Sci USA. 1999; 96:4512-17. https://doi. org/10.1073/pnas.96.8.4512.

32. Vindurampulle CJ, Attridge SR. Impact of vector priming on the immunogenicity of recombinant Salmonella vaccines. Infect Immun. 2003; 71:287-97. https://doi. org/10.1128/IAI.71.1.287-297.2003.

33. Barrow PA, Methner U. (Ulrich). Salmonella in domestic animals. 2013. 547.

34. Morrison DC, Ryan JL. Bacterial endotoxic lipopolysaccharides. Boca Raton (Fla.): CRC Press; 1992.

35. Cortiñas Abrahantes J, Bollaerts K, Aerts M, Ogunsanya V, Van der Stede Y. Salmonella serosurveillance: different statistical methods to categorise pig herds based on serological data. Prev Vet Med. 2009; 89:59-66. https://doi. org/10.1016/j.prevetmed.2009.01.009.

36. Hur J, Lee JH. Enhancement of immune responses by an attenuated Salmonella enterica serovar Typhimurium strain secreting an Escherichia coli heat-labile enterotoxin B subunit protein as an adjuvant for a live Salmonella vaccine candidate. Clin Vaccine Immunol. 2011; 18:203-09. https:// doi.org/10.1128/CVI.00407-10.

37. Van Amersfoort ES, Van Berkel TJ, Kuiper J. Receptors, mediators, and mechanisms involved in bacterial sepsis and septic shock. Clin Microbiol Rev. 2003; 16:379-414. https://doi.org/10.1128/CMR.16.3.379-414.2003.

38. Freudenberg MA, Merlin T, Gumenscheimer M, Kalis C, Landmann R, Galanos C. Role of lipopolysaccharide susceptibility in the innate immune response to Salmonella typhimurium infection: LPS, a primary target for recognition of Gram-negative bacteria. Microbes Infect. 2001; 3: 1213-22. https://doi.org/10.1016/S1286-4579(01)01481-2.

39. The UniProt Consortium. rfaL - O-antigen ligase Salmonella typhimurium (strain LT2/SGSC1412 / ATCC 700720) - rfaL gene; protein. 2016. Available 2016 Nov 23, from http://www.uniprot.org/uniprot/P26471.

40. Mulford CA, Osborn MJ. An intermediate step in translocation of lipopolysaccharide to the outer membrane of Salmonellatyphimurium. National Academy of Sciences; 1983; 80. https://doi.org/10.1073/pnas.80.5.1159.

41. Kim SW, Moon KH, Baik HS, Kang HY, Kim SK, Bahk JD, Hur J, Lee JH. Changes of physiological and biochemical properties of Salmonella enterica serovar Typhimurium by deletion of cpxR and lon genes using allelic exchange method. J Microbiol Methods. 2009; 79:314-20. https://doi. org/10.1016/j.mimet.2009.09.025.

42. Matsuda K, Chaudhari AA, Kim SW, Lee KM, Lee JH. Physiology, pathogenicity and immunogenicity of lon and/or cpxR deleted mutants of Salmonella Gallinarum as vaccine candidates for fowl typhoid. Vet Res. 2010; 41:59. https://doi.org/10.1051/vetres/2010031.

43. Holmgren J, Czerkinsky C. Mucosal immunity and vaccines. Nat Med. 2005; 11:S45-53. https://doi.org/10.1038/nm1213.

44. Mestecky J. The common mucosal immune system and current strategies for induction of immune responses in external secretions. J Clin Immunol. 1987; 7:265-76. https://doi.org/10.1007/BF00915547.

45. Buchmeier NA, Heffron F. Inhibition of macrophage phagosome-lysosome fusion by Salmonella typhimurium. Infect Immun. 1991; 59:2232-38.

46. Takaya A, Suzuki A, Kikuchi Y, Eguchi M, Isogai E, Tomoyasu T, Yamamoto T. Derepression of Salmonella pathogenicity island 1 genes within macrophages leads to rapid apoptosis via caspase-1- and caspase-3-dependent pathways. Cell Microbiol. 2005; 7:79-90. https://doi. org/10.1111/j.1462-5822.2004.00435.x.

47. Guiney DG. The role of host cell death in Salmonella infections. Curr Top Microbiol Immunol. 2005; 289:13150. https://doi.org/10.1007/3-540-27320-4_6.

48. Lee EJ, Park KS, Jeon IS, Choi JW, Lee SJ, Choy HE, Song KD, Lee HK, Choi JK. LAMP-3 (Lysosome-Associated 
Membrane Protein 3) Promotes the Intracellular Proliferation of Salmonella typhimurium. Mol Cells. 2016; 39:566-72. https://doi.org/10.14348/molcells.2016.0112.

49. Carrol ME, Jackett PS, Aber VR, Lowrie DB. Phagolysosome formation, cyclic adenosine $3^{\prime}: 5^{\prime}$-monophosphate and the fate of Salmonella typhimurium within mouse peritoneal macrophages. J Gen Microbiol. 1979; 110:421-29. https:// doi.org/10.1099/00221287-110-2-421.

50. Kohler JJ, Pathangey LB, Gillespie SR, Brown TA. Effect of preexisting immunity to Salmonella on the immune response to recombinant Salmonella enterica serovar typhimurium expressing a Porphyromonas gingivalis hemagglutinin. Infect Immun. 2000; 68:3116-20. https:// doi.org/10.1128/IAI.68.6.3116-3120.2000.

51. Gahan ME, Webster DE, Wijburg OL, Wesselingh SL, Strugnell RA. Impact of prior immunological exposure on vaccine delivery by Salmonella enterica serovar Typhimurium. Vaccine. 2008; 26:6212-20. https://doi. org/10.1016/j.vaccine.2008.09.060.

52. Datsenko KA, Wanner BL. One-step inactivation of chromosomal genes in Escherichia coli K-12 using PCR products. Proc Natl Acad Sci USA. 2000; 97:6640-45. https://doi.org/10.1073/pnas.120163297.

53. Lalsiamthara J, Lee JH. Pathogenic traits of Salmonella Montevideo in experimental infections in vivo and in vitro. Sci Rep. 2017; 7:46232. https://doi.org/10.1038/srep46232.
54. Alvarez J, Sota M, Vivanco AB, Perales I, Cisterna R, Rementeria A, Garaizar J. Development of a multiplex PCR technique for detection and epidemiological typing of salmonella in human clinical samples. J Clin Microbiol. 2004; 42:1734-38. https://doi.org/10.1128/ JCM.42.4.1734-1738.2004.

55. Bonet-Maury P, Jude A, Servant P. Statistical measurement of virulence and of immunity: application to the study of typhoid bacteria and to the measurement of immunizing power of antityphoid vaccines. [Article in Undetermined Language] Rev Immunol Ther Antimicrob. 1954; 18:21-49.

56. Bosseray N, Plommet M. Brucella suis S2, brucella melitensis Rev. 1 and Brucella abortus S19 living vaccines: residual virulence and immunity induced against three Brucella species challenge strains in mice. Vaccine. 1990; 8:462-68. https://doi.org/10.1016/0264-410X(90)90247-J.

57. Pouillot R, Grilló MJ, Alabart JL, Garin-Bastuji B, Blasco JM. Statistical procedures for calculating the residual virulence of Brucella abortus strain 19 (S19) and Brucella melitensis strain Rev 1 vaccines in mice: theoretical basis and practical applications. Rev Sci Tech. 2003; 22:1051-63. https://doi.org/10.20506/rst.22.3.1455.

58. Kang HY, Moon KH, Kim SW, Bahk JD, Gal SW, Cho K, Kim C, Lee JH, Kim SW. An efficient secretion of the protein fused to the AgfA signal sequence in Salmonella. African Journal of Biotechnology. 2011; 10:11611-9. 